\title{
Comparative whole genome sequence analysis of wild-type and cidofovir-resistant monkeypoxvirus
}

\author{
Jason Farlow*, Mohamed Ait Ichou, John Huggins and Sofi Ibrahim
}

\begin{abstract}
We performed whole genome sequencing of a cidofovir \{[(S)-1-(3-hydroxy-2-phosphonylmethoxy-propyl) cytosine] [HPMPC]\}-resistant (CDV-R) strain of Monkeypoxvirus (MPV). Whole-genome comparison with the wild-type (WT) strain revealed 55 single-nucleotide polymorphisms (SNPS) and one tandem-repeat contraction. Over one-third of all identified SNPs were located within genes comprising the poxvirus replication complex, including the DNA polymerase, RNA polymerase, mRNA capping methyltransferase, DNA processivity factor, and poly-A polymerase. Four polymorphic sites were found within the DNA polymerase gene. DNA polymerase mutations observed at positions 314 and 684 in MPV were consistent with CDV-R loci previously identified in Vaccinia virus (VACV). These data suggest the mechanism of CDV resistance may be highly conserved across Orthopoxvirus (OPV) species. SNPs were also identified within virulence genes such as the A-type inclusion protein, serine protease inhibitor-like protein SPI-3, Schlafen ATPase and thymidylate kinase, among others. Aberrant chain extension induced by CDV may lead to diverse alterations in gene expression and viral replication that may result in both adaptive and attenuating mutations. Defining the potential contribution of substitutions in the replication complex and RNA processing machinery reported here may yield further insight into CDV resistance and may augment current therapeutic development strategies.
\end{abstract}

\section{Background}

Poxviruses are large, enveloped, pleomorphic dsDNA viruses that infect a diverse array of mammals, reptiles, and insects [1]. The causative agent of Smallpox, Variola virus (VARV) is a member of the OPV genus. Smallpox was declared eradicated in 1980, however, natural or illicit re-emergence poses a risk for a growing non-vaccinated population [2]. MPV is a re-emerging pathogen within the OPV genus that causes sporadic outbreaks in monkeys and humans in West and Central Africa and, recently, in North America [3]. MPV can cause human disease clinically similar to Smallpox but with lower morbidity and mortality rates [4]. Although terrestrial and arboreal rodents and mammals are thought to play a role in MPV transmission, human to human transmission is known to occur [5].

Poxviruses possess large, complex genomes that encode their own viral replication machinery in addition to a plethora of immunomodulating proteins [1]. The major components of the poxviral replication complex include

\footnotetext{
* Correspondence: Jason.Farlow@us.army.mil

1 Virology Division, U.S. Army Medical Research Institute of Infectious Diseases, Fort Detrick, Frederick, MD 21702-5011, USA

Full list of author information is available at the end of the article
}

the poxvirus DNA polymerase (DNApol, E9L), transcription factor heterodimer (vETF), DNA-dependent RNA polymerase, RNA polymerase accessory protein (RAP94), viral poly-A polymerase (VP55/VP39), capping methyltransferase (D1/D10), and the DNA polymerase processivity factor (A20) [1,6]. Chemotherapeutic strategies for poxvirus infection have largely targeted viral DNA synthesis in order to disrupt the virus replication cycle $[7,8]$.

A number of nucleoside/nucleotide analogs are available that inhibit OPVs [7]. The acyclic nucleoside phosphonate analogue (S)-1-[3-hydroxy-2-phosphonylmethoxypropyl)] cytosine ((S)-HPMPC) or cidofovir (CDV) has been shown to inhibit in vitro viral replication of most known DNA viruses including poxviruses [9-11]. Recent studies suggest a mechanism whereby CDV may allosterically reposition the 3 nucleophile of terminal and short +strand synthesis products leading to aberrant chain extension $[12,13]$. Using the VACV DNApol E9L, previous studies indicate CDV incorporation slows chain elongation and inhibits DNA synthesis [12]. In addition, CDV has been shown to inhibit 3 ' to 5 ' exonuclease activity of E9L when incorporated in the penultimate position relative to the primer terminus [12]. By altering chain extension CDV affects DNA synthesis, a key regulator of 
poxvirus gene expression. Thus, alterations in gene expression and replication are likely to occur during CDV exposure, and, could result in mutations affecting conserved determinants of the virus life cycle.

Cidofovir activity appears to be conserved in dsDNA viruses providing a common strategy for inhibiting viral replication in important human diseases caused by these virus families $[14,8,15]$. Substitutions in the DNApol exonuclease $(\mathrm{A} 314 \mathrm{~T})$ and polymerase $(\mathrm{A} 684 \mathrm{~V})$ domains of the VACV DNA polymerase have previously been mapped and shown to confer CDV resistance $[16,17]$. CDV resistant strains in other members of the OPV genus, including MPV, Camelpoxvirus (CMPV), and Cowpoxvirus (CWPV) have already been reported [15]. DNApol mutations conferring resistance to CDV may be conserved among non-VACV OPV species although, presently, such sequence analyses have not been performed. Indeed, a portion of resistance attributes are likely to be conserved across dsDNA viruses. A number of additional features of CDV-resistance remain uncharacterized. CDV resistant strains frequently display an attenuated phenotype $[18,15]$ through yet uncharacterized natural genetic alterations. In addition, it has been suggested that, in some cases, resistance to CDV requires mutations outside the DNA polymerase. One previous study identified a CDV-R VACV which exhibited a single non-essential substitution in the DNApol that upon reconstruction did not confer CDV resistance [18]. To date, such loci elsewhere in the genome remain unknown. Whole-genome sequence data could provide valuable insight into breadth of mutations induced by CDV exposure and yield insight into further requisites for attenuation and resistance.

We report here the first whole genome sequence of a CDV-R poxvirus. Our data revealed a plethora of substitutions within the CDV-R MPV genome, one-third of which were distributed throughout the viral replication machinery. Substitutions identified in the MPV DNA polymerase are consistent with those previously observed in VACV suggesting CDV-resistance determinants may be conserved in the OPV genus. The numerous substitutions observed throughout the replication and RNA processing machinery suggest multiple accrued mutations may alter the timing and regulation of the virus life cycle under CDV exposure. Novel loci reported here may inform future studies aimed at mechanistic interaction of CDV with the replication complex.

\section{Results and Discussion}

Whole genome comparison of CDV-R and WT strains of Monkeypox revealed 55 single nucleotide polymorphisms (SNPs) including four insertions, six deletions, and 44 nucleic acid substitutions (Table 1, Figure 1, 2). A total of 10 intergenic and 45 intragenic SNPs, were observed that include 17 synonomous, 26 nonsynonomous substitutions and one tandem repeat contraction (Table 1). Over a third of all observed SNPs occurred within genes involved in virus replication and DNA metabolism. The physical distribution of all observed SNPs and indels (insertions/deletions) are illustrated in Figure 1.

\section{DNA replication}

Poxviruses exert exquisite control over the timing of gene expression to regulate genome replication and virion assembly [19]. Five early proteins are essential for poxvirus DNA replication, including the DNA polymerase (E9), DNA-independent nucleoside triphosphatase (NTPase, D5), uracil DNA glycosylase (D4), protein kinase B1, and DNA processivity factor (VPF/A20) $[19,6]$. In our study, substitutions were observed in the $3^{\prime}$ to $5^{\prime}$ exonuclease and 5 ' to 3 ' polymerase domains of the MPV DNA polymerase (Table 1, Figure 2, Figure 3A, B) consistent with previous studies in VACV $[10,12,20]$. A total of four non-synonomous substitutions and 1 synonymous substitution were observed in the MPV DNA polymerase gene (ORF 062) (Table 1). The CDV-R MPV DNApol encoded substitutions A314V and A684T at conserved positions respective to CDV-R VACV [16], although the substituted residues appear reversed $(\mathrm{MPV}=\mathrm{V} 314 / \mathrm{T} 684$, $\mathrm{VACV}=\mathrm{T} 314 / \mathrm{V} 684)$. In both cases, A314 and A684 in MPV and VACV are replaced by slightly larger residues with differing polar characters (threonine $=+4.9$, valine $=$ -2.0). Two novel substitutions A613T and T808M in the MPV CDV-R strain were located within and flanking the polymerase domain, respectively (Figure 2 ).

We utilized predictive modeling software to extrapolate potential structural changes mediated by these substitutions in the MPV DNA polymerase protein. Predicted topological features of the CDV-R DNA polymerase A314V substitution in the exonuclease domain appears to increase the regional hydrophobicity, alter surface contour and decrease surface exposure (Figure 4A, B, Figure $5 \mathrm{~A}, \mathrm{~B}, \mathrm{C}$, Table 2) at this locus. The A684T substitution in the polymerase domain appears to exhibit a decrease in the regional hydrophobicity (Figure 5D) and an increase in surface contour and exposure (Figure 5E, F), including a predicted shift from alpha helical to beta sheet topology (Figure 6A, B). Similar analysis suggests a slight increase in surface exposure at the A613T locus and a moderate loss of surface exposure at the T808M locus (Table 2). It has been hypothesized that the resistant mutation at the A314 locus in the exonuclease domain may facilitate excision of CDV during replication, while mutation at A684, located adjacent to the DNA-binding pocket (Figure 3A, $B)$, may be involved in nucleotide selection and discrimination of CDV [20]. Solving the 3-D structure of a poxvi- 

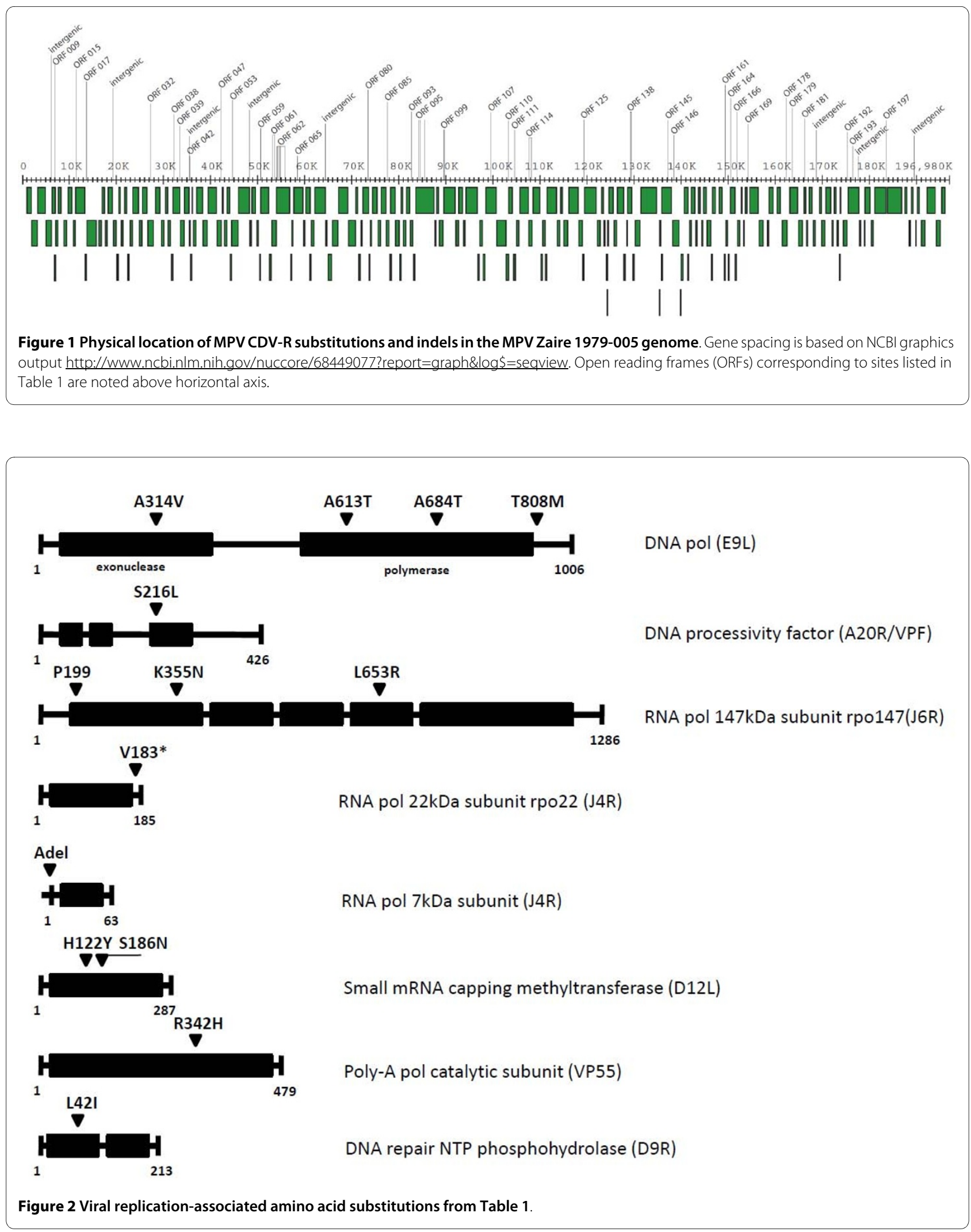
Table 1: Genome-wide SNP/indel attributes of CDV-R MPV.

\begin{tabular}{|c|c|c|c|c|c|c|}
\hline Location ${ }^{a}$ & Mutation & Amino Acid & Z79-ORFb & COP-ORFC & Gene & GenBank\# \\
\hline 6166 & T insertion & NA & $\mathrm{IG}^{d}$ & NA & NA & NA \\
\hline 6863 & $\mathrm{G}$ to $\mathrm{A}$ & P9S & 9 & unknown & ankyrin-like & AAY97204 \\
\hline 11360 & $\mathrm{~T}$ insertion & NA & 15 & unknown & ankyrin/host Range & AAY97210 \\
\hline 13685 & $\mathrm{C}$ to $\mathrm{T}$ & A589T & 17 & C9L & ankyrin & AAY97212 \\
\hline 19143 & $\mathrm{C}$ to $\mathrm{T}$ & NA & $\mathrm{IG}^{d}$ & NA & NA & NA \\
\hline 27141 & C deletion & A168Q & 32 & $\mathrm{~K} 2 \mathrm{~L}$ & $\begin{array}{l}\text { serine protease inhibitor-like protein } \\
\qquad \mathrm{SPI}-3\end{array}$ & AAY97227 \\
\hline 32192 & T deletion & H385L & 38 & F3L & Kelch-like & AAY97233 \\
\hline 33518 & $\mathrm{C}$ to $\mathrm{T}$ & silent & 39 & 14L/F4L & ribonucleoside-diphosphate reductase & AAY97234 \\
\hline 35560 & T deletion & NA & $\mathrm{IG}^{d}$ & NA & NA & NA \\
\hline 35593 & $\mathrm{G}$ to $\mathrm{A}$ & T68M & 42 & F7L & unknown & AAY97237 \\
\hline 40212 & $C$ to $A$ & silent & 47 & F12L & IEV associated & AAY97242 \\
\hline 44808 & $\mathrm{C}$ to $\mathrm{T}$ & $\mathrm{R} 342 \mathrm{H}$ & 53 & E1L & $\begin{array}{l}\text { poly-A polymerase catalytic subunit } \\
\text { VP55 }\end{array}$ & AAY97248 \\
\hline 48134 & A to $T$ & NA & $\mathrm{IG}^{d}$ & NA & NA & NA \\
\hline 50728 & T to $A$ & silent & 59 & E6R & unknown & AAY97254 \\
\hline 53128 & $T$ to $C$ & silent & 61 & E8R & $\begin{array}{l}\text { assoc.s with IV/IMV and cores; F10L } \\
\text { kinase substrate }\end{array}$ & AAY97256 \\
\hline 53738 & $\mathrm{G}$ to $\mathrm{A}$ & V256I & 61 & E8R & $\begin{array}{l}\text { assoc.s with IV/IMV and cores; F10L } \\
\text { kinase substrate }\end{array}$ & AAY97256 \\
\hline 54066 & $T$ to $C$ & silent & 62 & E9L & DNA polymerase & $\underline{\text { AAY97257 }}$ \\
\hline 54400 & $\mathrm{G}$ to $\mathrm{A}$ & T808M & 62 & E9L & DNA polymerase & AAY97257 \\
\hline 54773 & $C$ to $T$ & A684T & 62 & E9L & DNA polymerase & AAY97257 \\
\hline 54986 & $\mathrm{C}$ to $\mathrm{T}$ & А613T & 62 & E9L & DNA polymerase & AAY97257 \\
\hline 55882 & $\mathrm{G}$ to $\mathrm{A}$ & A314V & 62 & E9L & DNA polymerase & AAY97257 \\
\hline 58655 & $T$ to $C$ & silent & 65 & $01 \mathrm{~L}$ & unknown & $\underline{\text { AAY97260 }}$ \\
\hline 64425 & A insertion & NA & $\mathrm{IG}^{d}$ & NA & NA & NA \\
\hline 73563 & A deletion & NA & $\mathrm{IG}^{d}$ & NA & NA & NA \\
\hline 77811 & $\mathrm{G}$ to $\mathrm{A}$ & M207I & 85 & L1R & myristylprotein & AAY97280 \\
\hline 82937 & $\mathrm{C}$ to $\mathrm{T}$ & silent & 93 & $J 4 R$ & $\begin{array}{l}\text { DNA-dependent RNA polymerase } \\
\text { subunit rpo22 }\end{array}$ & AAY97288 \\
\hline 84110 & $\mathrm{G}$ to $\mathrm{A}$ & silent & 95 & $J 6 R$ & $\begin{array}{l}\text { DNA-dependent RNA polymerase } \\
\text { subunit rpo147 }\end{array}$ & AAY97290 \\
\hline 84578 & A to $C$ & $\mathrm{~K} 355 \mathrm{~N}$ & 95 & $J 6 R$ & $\begin{array}{l}\text { DNA-dependent RNA polymerase } \\
\text { subunit rpo147 }\end{array}$ & $\underline{\text { AAY } 97290}$ \\
\hline 85471 & $T$ to $G$ & L653R & 95 & $J 6 R$ & $\begin{array}{l}\text { DNA-dependent RNA polymerase } \\
\text { subunit rpo147 }\end{array}$ & AAY97290 \\
\hline 89604 & $\mathrm{G}$ to $\mathrm{A}$ & silent & 99 & $\mathrm{H} 4 \mathrm{~L}$ & $\begin{array}{l}\text { RNA polymerase-assoc. transcription } \\
\text { factor RAP94 }\end{array}$ & AAY97294 \\
\hline 89691 & $\mathrm{C}$ to $\mathrm{T}$ & M715I & 99 & $\mathrm{H} 4 \mathrm{~L}$ & $\begin{array}{l}\text { RNA polymerase-assoc. transcription } \\
\text { factor RAP94 }\end{array}$ & $\underline{\text { AAY } 97294}$ \\
\hline 99891 & $\mathrm{~T}$ to $\mathrm{C}$ & silent & 107 & D5R & NTPase, DNA replication & AAY97302 \\
\hline 103281 & $\mathrm{C}$ to $\mathrm{T}$ & A289T & 110 & D8L & carbonic anhydrase/Virion & AAY97305 \\
\hline 104948 & $\mathrm{C}$ to $\mathrm{A}$ & L42I & 111 & D9R & nudix-hydrolase/RNA decapping & AAY97307 \\
\hline 107809 & $\mathrm{C}$ to $\mathrm{T}$ & $\mathrm{H} 122 \mathrm{Y}$ & 114 & D12L & $\begin{array}{l}\text { small capping enzyme, } \\
\text { methyltransferase }\end{array}$ & $\underline{\text { AAY97309 }}$ \\
\hline
\end{tabular}


Table 1: Genome-wide SNP/indel attributes of CDV-R MPV. (Continued)

\begin{tabular}{|c|c|c|c|c|c|c|}
\hline 108002 & $G$ to $A$ & S186N & 114 & D12L & $\begin{array}{l}\text { small capping enzyme, } \\
\text { methyltransferase }\end{array}$ & AAY97309 \\
\hline 119244 & $\mathrm{G}$ to $\mathrm{A}$ & silent & 125 & A9L & membrane protein & AAY97320 \\
\hline 129030 & $\mathrm{C}$ to $\mathrm{T}$ & S216L & 138 & $\mathrm{~A} 20 \mathrm{R}$ & DNA processivity factor & $\underline{\text { AAY97333 }}$ \\
\hline 129340 & $\mathrm{G}$ to $\mathrm{A}$ & silent & 138 & A20R & DNA processivity factor & AAY97333 \\
\hline 137047 & A to $G$ & L324S & 145 & A25L & A type inclusion protein (CPXV) & $\underline{\text { AAY97340 }}$ \\
\hline 138486 & $\begin{array}{l}\text { ATCATC } \\
\text { deletion }\end{array}$ & DD-dele & 146 & A26L & $\begin{array}{l}\text { P4c: CWPVA27L, A-type inclusion } \\
\text { protein }\end{array}$ & AAY97341 \\
\hline 149213 & $\mathrm{G}$ to $\mathrm{A}$ & silent & 161 & $\mathrm{~A} 42 \mathrm{R}$ & profilin homolog & $\underline{\text { AAY97356 }}$ \\
\hline 150527 & $\mathrm{C}$ to $\mathrm{T}$ & A284T & 164 & A44L & $\begin{array}{c}\text { bifunctional hydroxysteroid } \\
\text { dehydrogenase }\end{array}$ & $\underline{\text { AAY97356 }}$ \\
\hline 151960 & $\mathrm{~T}$ to $\mathrm{C}$ & silent & 166 & A46R & IL-1 signaling inhibitor & $\underline{\text { AAY97361 }}$ \\
\hline 154086 & G deletion & frameshift & 169 & A48R & thymidylate kinase & AAY97364 \\
\hline 162118 & $\mathrm{C}$ to $\mathrm{T}$ & $\mathrm{H} 268 \mathrm{Y}$ & 178 & $\mathrm{~B} 2 \mathrm{R} / \mathrm{B} 3 \mathrm{R}$ & Schlafen ATPase & $\underline{\mathrm{AAY} 97370}$ \\
\hline 163857 & $\mathrm{C}$ to $\mathrm{T}$ & A271V & 179 & B4R & ankyrin & AAY97371 \\
\hline 166078 & A to $T$ & Q9H & 181 & B6R & ankyrin & $\underline{\text { AAY97373 }}$ \\
\hline 168859 & $T$ to $A$ & NA & $\mathrm{IG}^{d}$ & NA & NA & NA \\
\hline 175168 & $\mathrm{C}$ to $\mathrm{T}$ & silent & 192 & B18R & IFN- $\alpha / \beta$-receptor orthologue & AAY97385 \\
\hline 176348 & $\mathrm{~T}$ to $\mathrm{C}$ & silent & 193 & unknown & ankyrin & AAY97386 \\
\hline 177838 & Tinsertion & NA & $\mathrm{IG}^{d}$ & NA & NA & NA \\
\hline 183499 & $\mathrm{~T}$ to $\mathrm{C}$ & silent & 197 & CWP_B22R & surface glycoprotein & AAY97391 \\
\hline 189631 & T to $C$ & NA & $\mathrm{IG}^{d}$ & NA & NA & NA \\
\hline 190055 & A deletion & NA & $\mathrm{IG}^{d}$ & NA & NA & NA \\
\hline
\end{tabular}

rus DNApol may provide further clarity on the positional activity and functional attributes of these mutations.

\section{DNA processivity factor}

Fully processive DNA polymerase activity is mediated by the heterodimeric A20/D4 DNA processivity factor [21]. A20 is essential for genome replication and may form a multi-enzyme replication complex with D4, D5, and H5 that is postulated to stabilize the DNA replication complex [22]. D5R is a nucleic acid independent nucleoside triphosphatase (NTPase) that is crucial for infection $[23,24]$ and may play a role in priming DNA synthesis at the replication fork [25]. In our study, CDV-R MPV exhibited a substitution in A20 (S216L) that lies directly within the D5 NTPase/primase binding domain (Table 1, Figure 2) [22,26].

\section{Thymidylate kinase}

The poxvirus thymidylate kinase (TMPK) encodes a 48 $\mathrm{kDa}$ serine threonine protein kinase (A48R) [27] that regulates deoxyribonucleotide triphosphate pools in con- junction with the viral thymidine kinase. Similar to cellular TMPK, A48R functions as a homodimer where dimerization is mediated by proper orientation of the $\alpha 2$, $\alpha 3, \alpha 6$ helices [28]. The quaternary structure of A48R is distinct in orientation from that of the host conferring broader substrate specificity [28]. We observed a SNP deletion at residue 600 in the CDV-R MPV gene that results in a frameshift mutation at amino acid Q201 and replacement of the c-terminus residues "QLWM" with residues "NCGC" (Table 1, Figure 7 and inset). The frameshift results in a more pronounced turn region conferred by the proximal P198 predicted by chou-Fasman and Gernier-Robson algorithms (data not shown). This alteration may affect the dimerization interface of the homodimer given that the c-terminal residues support the $\alpha 6$ helix which mediates dimerization (Figure 7)[28]. It is interesting to speculate whether such a change in secondary structure could affect protein function during CDV exposure, such as discriminatory selection between CDV diphosphate and cellular dCTP pools. 

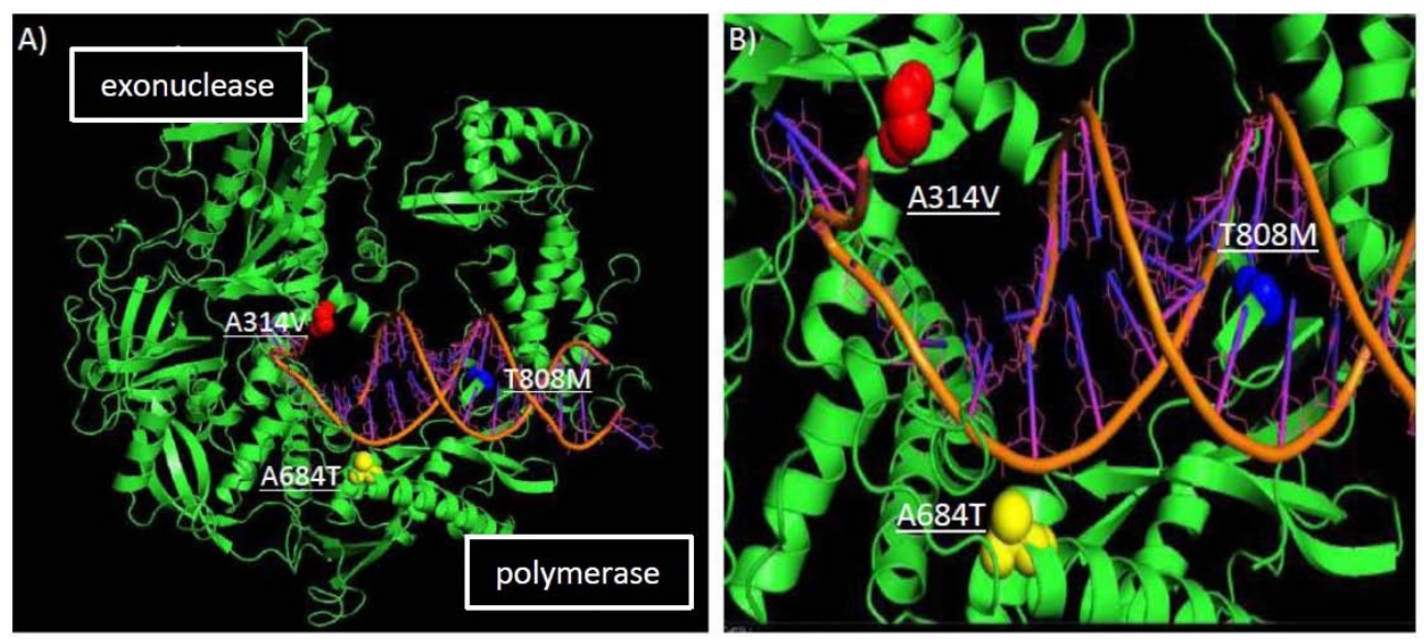

Figure 3 MPV CDV-R mutations mapped onto the 3D structures of herpes simplex 1 DNA polymerase. Mutations A314V (red), A684T (yellow), and T808M (blue) are illustrated in view of the entire protein (A) and DNA binding cleft (B).

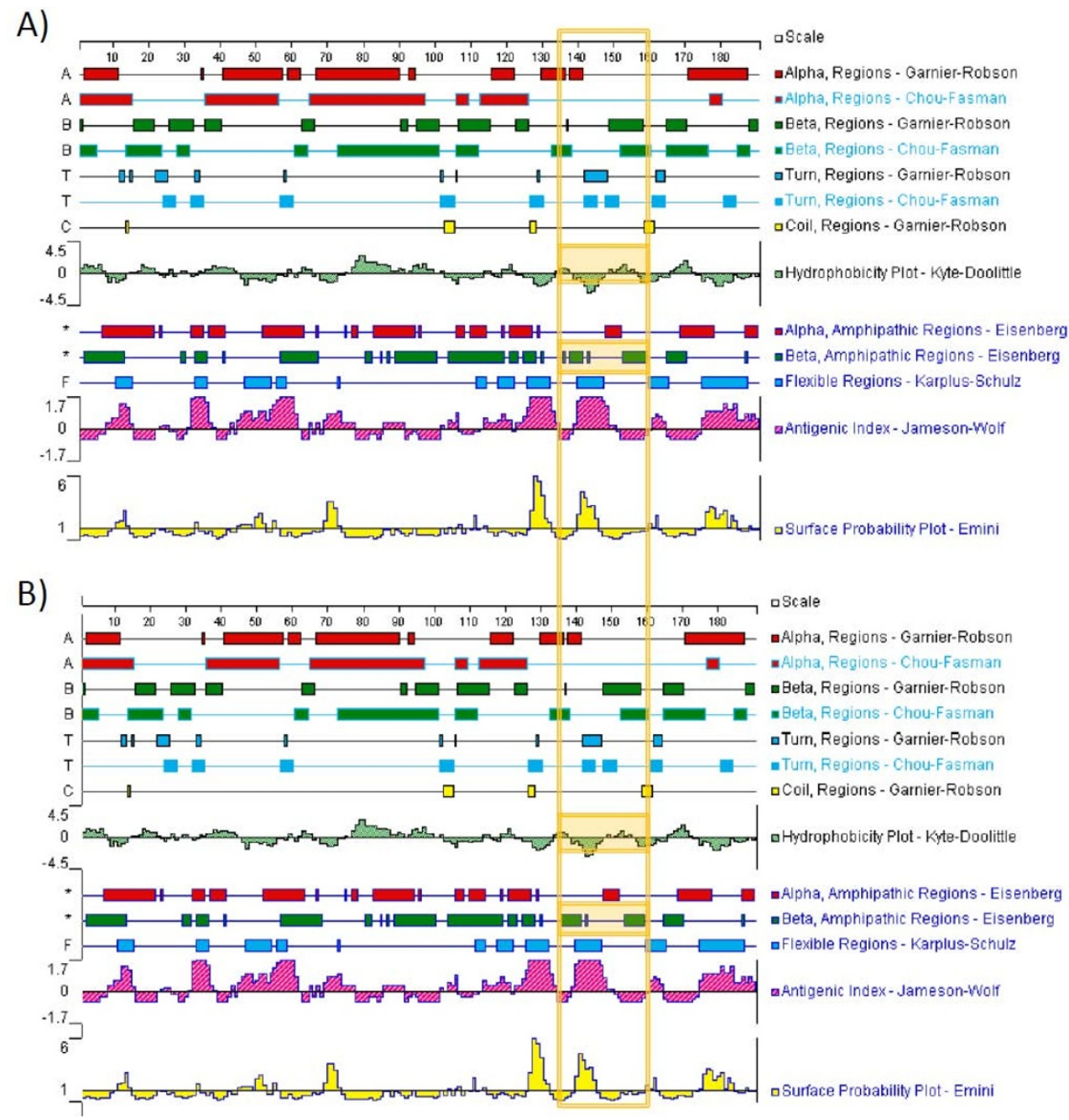

Figure 4 Topological feature maps of CDV-R (A) and WT (B) MPV DNA pol 3'-5' exonuclease domain. Plotted residues 1-190 correspond to 162351 in the MPV DNA pol exonuclease domain. The A314V substitution (Table 1) corresponds to position 153 in the plot. For comparison, regions of difference in secondary structure and biochemical characteristics between CDV-R and WT are designated by shaded areas in the vertical orange box. 


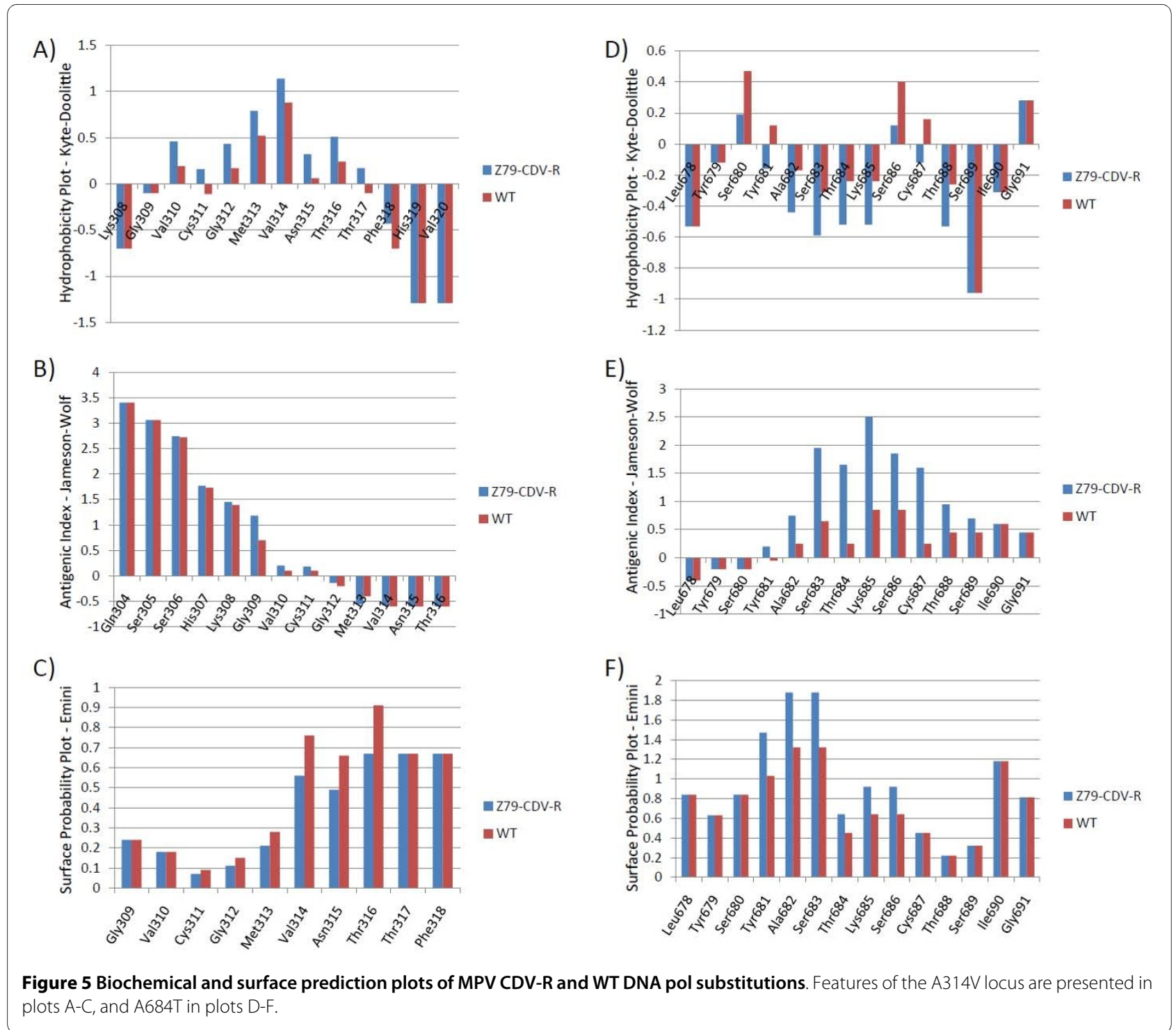

\section{RNA polymerase machinery}

The primary components of the poxviral RNA machinery consist of the poxvirus DNA-dependent RNA polymerase (rpo147), the viral early transcription factor vETF (D1/ D12) heterodimer, eight RNA polymerase subunits, RAP94, VP55/VP39 subunits of the viral poly (A) polymerase, the capping methyltransferase (D1/D12), and the D9 subunit of the mRNA decapping enzyme (Table 1, Figure 2) [1]. Proteins RAP94, NPHI (D11), and D1/D12 constitute early termination factors [19]. Poxvirus RNA pol contains eight common subunits including rpo147, rpo132, rpo35, rpo30, rpo22, rpo19, rpo18, rpo7 [1]. The dual functional ninth subunit, RAP94, is absent in intermediate and late replication complexes [29] and is thought to function as an early transcription factor docking platform [30,31]. Vaccinia Early Transcription Factor (VETF), comprising D6R and A7L, binds to early promoters, recruits RAP94-containing RNA pol, and nucleates a stable pre-initiation complex at the early promoter [31]. Viral mRNA capping and addition of poly(A) tails are generated by the heterodomeric proteins D1/D12 and VP55/VP39, respectively [32-34]. In addition, cellular RNA pol II and TATA-binding proteins (TBPs) are recruited to poxvirus replication complexes, possibly to early and late viral promoters that show similarity to cellular RNA pol II TATA-box promoters [35,36]. Roles for such host proteins in the viral life cycle remain unknown. Several poxviral RNA polymerase subunits share limited sequence similarity with cellular RNA pol II subunits [36]. Previous studies indicate the largest subunit of the poxvirus RNApol (rpo147) exhibits the greatest homology to cellular RNApol II [37,38] while vaccinia VETF (D1-D12) and RAP94 show sequence similarity to cellular TBP-TFIID and RAP30-TFIIF, respectively [39]. In this study, we observed amino acid substitutions in MPV RNA pol II subunits including rpo147 (K355N, L653R), 


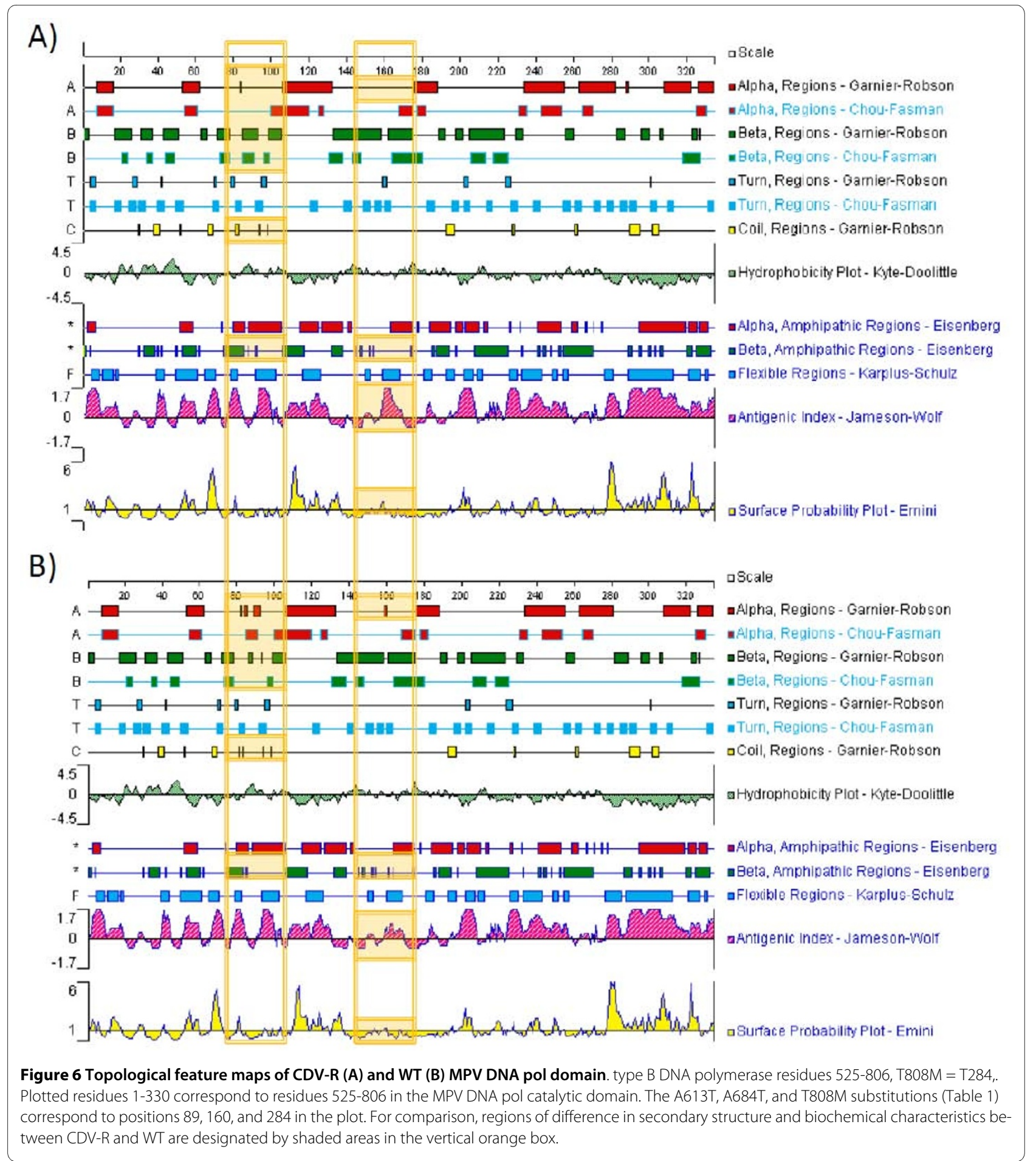

RAP94 (M715I), VP55 (R342H), D12 (H122Y, S186N), and D9 (L42I) (Table 1, Figure 2).

\section{RNA polymerase rpo147}

The L653R substitution in the poxvirus rpo147 subunit lies directly in a homologous region of domain 4 in the yeast RNA polymerase II (RNA pol II) Rpb1 subunit (yeast E734R) that comprises the funnel (secondary channel) domain (Figure 8A, B, C) [40]. The domain lies at the juncture of the catalytic domain and the outside medium and is thought to mediate NTP entry and selection and support exonuclease proofreading [40]. The funnel domain may mediate binding RNA cleavage stimulatory factor TFIIS (Figure 9B) [41], which stimulates RNA pol 
Table 2: Biochemical and topological attributes of CDV-R MPV mutations

\begin{tabular}{|c|c|c|c|c|c|c|c|}
\hline Protein & ORFa & Amino Acid & Domain & Polarity $^{b}$ & Hydropathyb & $\begin{array}{c}\text { Surface } \\
\text { Exposure }^{d}\end{array}$ & $\begin{array}{c}\text { Surface } \\
\text { Contoure }\end{array}$ \\
\hline DNA pol & E9L & A314V & exonuclease & 0.1 & 2.4 & decrease & increase \\
\hline DNA pol & E9L & А613T & polymerase & 6.8 & 2.5 & increase & increase \\
\hline DNA pol & E9L & A684T & polymerase & 6.8 & 2.5 & increase & increase \\
\hline DNA pol & E9L & T808M & NA & 6.4 & 2.6 & decrease & decrease \\
\hline $\begin{array}{l}\text { RNA pol } \\
\text { subunit rpo147 }\end{array}$ & $J 6 R$ & K355N & TFIIB docking & 5.3 & 3.12 & decrease & increase \\
\hline $\begin{array}{l}\text { RNA pol } \\
\text { subunit rpo147 }\end{array}$ & $J 6 R$ & L653R & funnel & 22.3 & 8.3 & increase & increase \\
\hline $\begin{array}{l}\text { mRNA capping } \\
\text { enzyme small } \\
\text { subunit }\end{array}$ & $\mathrm{D} 12 \mathrm{~L}$ & $\mathrm{H} 122 \mathrm{Y}$ & dimerization & 4.2 & 1.9 & increase & decrease \\
\hline $\begin{array}{l}\text { mRNA capping } \\
\text { enzyme small } \\
\text { subunit }\end{array}$ & $\mathrm{D} 12 \mathrm{~L}$ & $\mathrm{~S} 186 \mathrm{~N}$ & dimerization & 4.6 & 2.7 & increase & decrease \\
\hline $\begin{array}{l}\text { poly-A pol } \\
\text { catalytic } \\
\text { subunit VP55 }\end{array}$ & E1L & $\mathrm{R} 342 \mathrm{H}$ & dimerization & 9.7 & 0.7 & decrease & decrease \\
\hline
\end{tabular}

II nuclease activity following transcriptional arrest [42] and recruits RNA pol II and TFIIB to the promoter [43]. In addition, this domain is also the binding site for antimicrobial RNA pol inhibitors including $\alpha$-amanitin and targetoxin [44-46]. The MPV CDV-R L653R substitution lies adjacent to residues previously shown to mediate cellular RNA pol II inhibitor $\alpha$-amanitin resistance (Figure $8 \mathrm{~B}$ and $8 \mathrm{C}$ ) [45]. Protein structure prediction indicates the L653R mutation may decrease regional hydrophobicity, and increases motif surface exposure (Table 2). The extent of homology of poxviral rpo147 and rpo30 with cellular RNA pol II Rpb 1 and TFIIS [38,47] suggest general features of their interaction may be conserved.

The MPV CDV-R K355N substitution (yeast G422) lies directly within the docking domain near the RNA exit groove of RNA pol II (Figure 8A and 9A)[48]. The RNA pol II docking domain binds TFIIB through contact residues 407-RDSGDRIDLRYSK-419 located within a larger conserved 67 amino acid motif [48]. The MPV CDV-R K355N mutation lies within the docking domain (in purple) immediately adjacent to the contact residue motif (Figure 9A). A significant change in predicted secondary structure is imparted by the K355N substitution including a pronounced increase in the surface contour (Table 2 ). The effect of CDV on the viral and cellular RNA polymerase machinery has not been evaluated. It is possible that viral RNA pol may be subject to either direct or indirect effects of CDV via dCTP selection in the presence of
CDV or transcriptional arrest due to disrupted mRNA transcripts. In any case, alteration of the functional activity of either the funnel or docking domain could significantly alter pre-initiation complex formation and affect transcriptional regulation and promoter recruitment.

\section{Capping methyltransferase}

The poxvirus mRNA capping machinery, encoded by the D1R and D12L genes in VACV, catalyzes viral mRNA capping and regulates gene transcription $[49,50]$. The D1/ D12 heterodimer mediates 5 methylation of viral transcripts [32], promotes early gene transcription termination [51], and regulates initiation of intermediate gene expression [52]. Methyltransferase (MT) catalysis is mediated by the C-terminal active domain of D1R. Triphosphatase and quanylyltransferase activity are located within the N-terminal domain [53]. Following heterodimerization, the stimulatory D12 subunit confers full D1R MT activity by stimulating MT catalysis up to 50 fold $[54,55]$.

We observed two substitutions (H122Y and S186N) in the MPV CDV-R strain D12 orthologue (ORF114) (Table 1, Figure 2). Both substitutions lie within structural motifs that mediate allosteric interactions important for D1-D12 heterodimerization and MT activity (Figure 10A and $10 \mathrm{~B}$, in red and yellow) $[53,56]$. The basic $\mathrm{H} 122$ residue flanks two neutral residues, $120 \mathrm{~N}$ and $121 \mathrm{~N}$, that affect important polar interactions between D1 and D12 


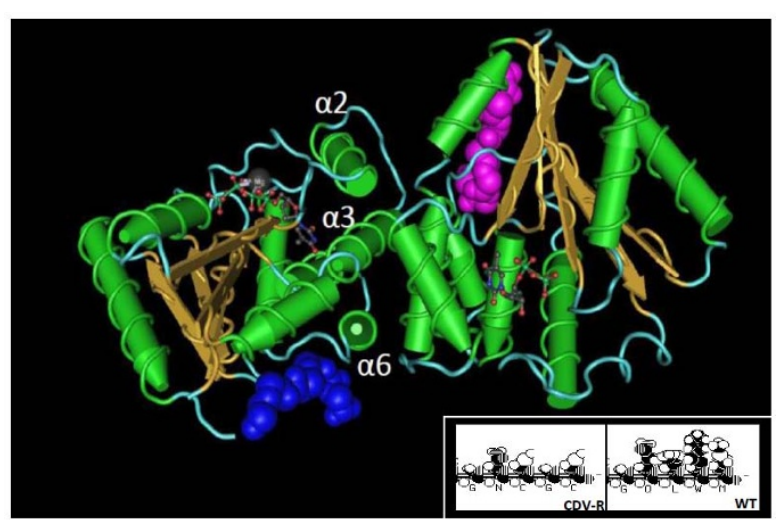

Figure 7 MPV CDV-R c-terminal amino acid deletion mapped on 3-D structure of VACV thymidylate kinase (TMPK) homodimer The four residues corresponding to the c-terminal frameshift mutation in MPV CDV-R are labeled in blue and pink. Illustrations were prepared using Cn3D. Inset includes space-filling model of the four c-terminal residues of WT and CDV-R MPV TMPK (prepared using Lasergene software).

(Figure 10A and 10B, in blue)[53,56]. CDV-R residue Y122 lies directly within an 11-aa motif (119-130) in the central domain region that plays a direct role in heterodimerization (yellow residues shown in Figure 10A and 10B) [53]. In addition, this short motif forms inter-subunit contacts with the D1R N-terminal $\alpha-\mathrm{Z}$ helix and is proposed to allosterically stabilize substrate binding by D1R [53]. Predicted changes in secondary structure due to the H122Y substitution indicate a beta strand reduction (data not shown) and decreased surface contour and exposure (Table 2). Residue S186 lies with the conserved motif 183-KCVSDSWLKDS (red residues Figure 6F) that was previously noted as a highly structured motif which integrates several local and distal interactions which may play a major role in proper tertiary folding [53]. This position also flanks motif 189-WLKDS that may constitute a portion of the D1 subunit docking site [53]. S186 is in closest proximity to D1 residues S589 (teal) and T84 (magenta) (Figure 10A) and lies near the D1-D12 interface (Figure 10B).

D12 structurally stabilizes D1 through allosteric interactions that mediate heterodimerization and substrate affinity [57]. Predicted changes in secondary structure observed here could affect the D12/D1 interface, and thereby possibly alter viral gene expression. Affecting D1/ D12 heterodimerization has previously been proposed as a potential therapeutic target for rational drug design [58]. We also observed an L42I substitution in the D9 subunit of the mRNA decapping enzyme (Table 1) that acts primarily on early transcripts [59]. The L42 residue appears highly conserved throughout the Chordopoxvirinae [59]. The D9/D10 heterodimeric decapping enzyme has been shown to decrease the levels of viral and cellular capped mRNAs and their translated products perhaps to delineate more responsive transitions between early and late stage gene expression [59].

\section{VP55 poly (A) polymerase}

Similar to eukaryotic mRNA transcripts, viral mRNAs possess a $\mathrm{m} 7 \mathrm{G}\left(5^{\prime}\right)$ pppGm cap structure and a 3' poly(A) tail. This posttranscriptional modification is carried out by the viral capping heterodimer VP39 and the heterodimeric poly $(\mathrm{A})$ polymerase (PAP) protein that catalyzes $3^{\prime}$ adenylate extension [33,34]. The large subunit of PAP is the catalytically active VP55 poly(A) polymerase and requires the small subunit (VP39) for full processivity [60]. VP39 performs dual functions and exhibits methyltransferase activity distinct from its role as a processivity factor for VP55 polyadenylation. VP55 acquires processivity by binding VP39 at a dimerization surface region distal to the VP39 methyltransferase cleft [61]. Conformational changes from this interaction occur in the VP39 methyltransferase, and VP55-VP39 interaction has been shown to positionally alter the VP55 RNA contact site [62].

We observed an $\mathrm{R} 342 \mathrm{H}$ substitution (Table 1) within the VP55 $C$ domain dimerization region interface of VP39 and VP55 (Figure 11A, B) [63]. Predictive modeling suggests that the $\mathrm{R} 342 \mathrm{H}$ substitution decreases regional surface exposure (C domain residues 337-344) and induced a flexible coil region at the 342 locus (data not shown). Such alterations in the secondary structure within this region could alter both the VP55-VP39 interaction interface (yellow dashed line - Figure 11B) as well as the upstream proximal linker segment that supports the catalytic domain of VP55 [63]. Previously, nucleotide analogs have been postulated to negatively affect polyadenylation and early mRNA extrusion from the viral core [64]. In addition, nucleotide content within VP55 oligonucleotide primer recognition motifs may affect the timing of gene expression [64]. As a cytosine analog, $\mathrm{CDV}$, if incorporated into priming sequences, could alter the primer reaction site and impart some selection pressure to maintaining effective VP55-primer recognition and subsequent processive polyadenylation of mRNA transcripts.

\section{Conclusion}

In the current study we report the complete genomic sequence of a CDV-R strain of MPV. In addition, we present a focused and comparative bioinformatic analysis that revealed predicted alterations in topological features of functionally active domains within essential virus proteins. Previous data indicate mutations at sites 314 and 684 in the DNApol represent the primary determinants of CDV-R in VACV $[15,20]$. Although second-site substitutions elsewhere in the VACV genome have been impli- 


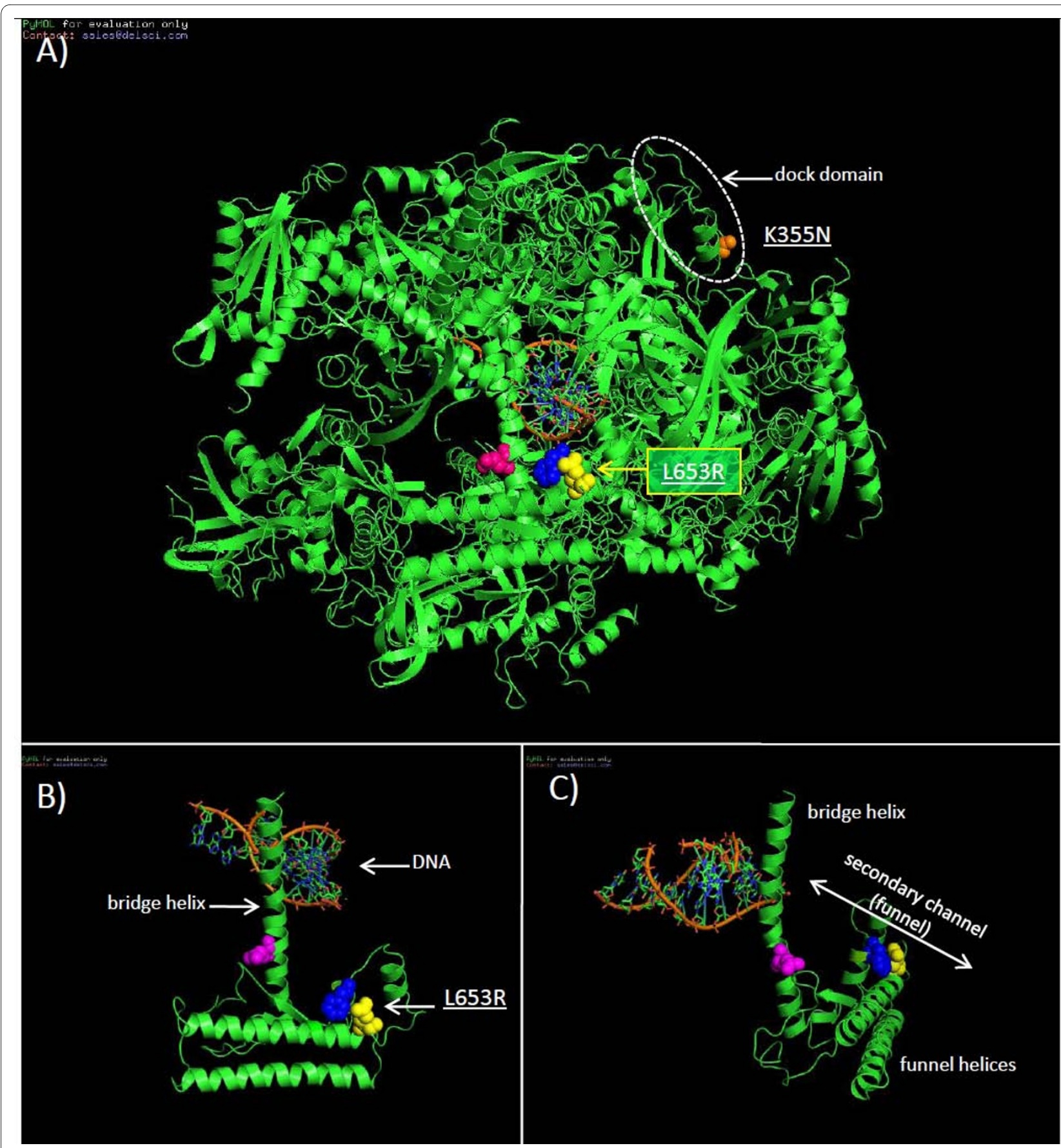

Figure 8 MPV CDV-R substitutions mapped onto the 3-D structure of S. cerevisiae RNA pol II (GenBank \# CAA65619.1). The MPV CDV-R L653R residue mapped to the yeast RNA pol II funnel domain is designated in yellow (A-C). The MPV CDV-R K355N residue mapped to the docking domain of yeast RNA pol II is designated in orange. Yeast residues Leu737 (blue) and Phe755 (magenta) are associated with a-amanitin resistance [46]. IIlustrations were prepared using PyMol.

cated previously in a CDV-R clone [18], they have yet to be identified. The present study may provide clues to the location of such mutations. The MPV DNApol mutations reported here provide the first indication that CDV-R loci previously identified in VACV are perhaps conserved in fully-virulent, non vaccine strains, though such specula- tion must await experimental validation. Such data may inform efforts in development of Smallpox-related medical countermeasures. Any direct effects of selected mutations reported here on the resistant or attenuated phenotype of MPV must await future determination. These regions may be of particular interest for future site- 


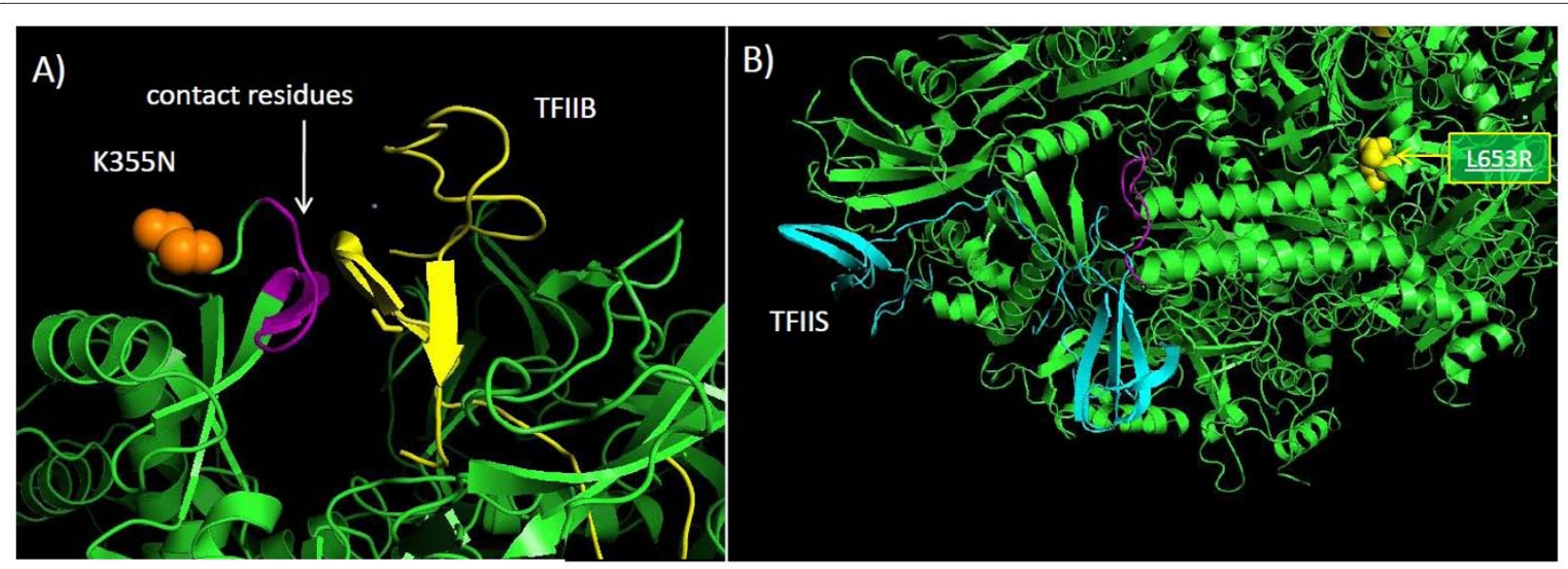

Figure 9 MPV CDV-R RNA pol substitutions mapped onto the 3-D structure of S. cerevisiae RNA pol II. CDV_R substitution K355N (orange) and L653R (yellow) mapped to the 3-D structure of A) binding sites of TFIIB (purple) on yeast RNA pol II and B) TFIIS (teal) [70], respectively. Illustrations were prepared using PyMol.

directed mutagenesis studies to dissect 1 ) potential yetuncharacterized mutations elsewhere in the genome that may play a role in the CDV-R phenotype, and, 2) the genetic basis of the characteristic attenuated phenotype of CDV-R poxviruses. It is possible the substitutions observed in our analysis outside the viral DNA polymerase, for example in the RNA polymerase and mRNA capping enzyme, may contribute to the resistant or attenuated phenotype of CDV-R MPV. Such changes may represent compensatory, adaptive, or attenuating variations in gene expression or replication. Also, adaptive substitutions which support a CDV-R phenotype may result in alterations in the timing of the viral gene expression program that could reduce fitness compared to wild-type yet sustain gene expression in the presence of CDV. Both adaptive and non-adaptive substitutions may also be facilitated through mutator alleles in the DNA or RNA polymerases. As DNA synthesis is a key regulator of gene expression in poxviruses, it is possible the aberrant chain extension induced by CDV may lead to diverse alterations in gene expression and replication that must be overcome by a resistant strain. The genome sequence of CDV-R MPV may inform future research into the mechanism of action of CDV as well as dissection of the phenotypic
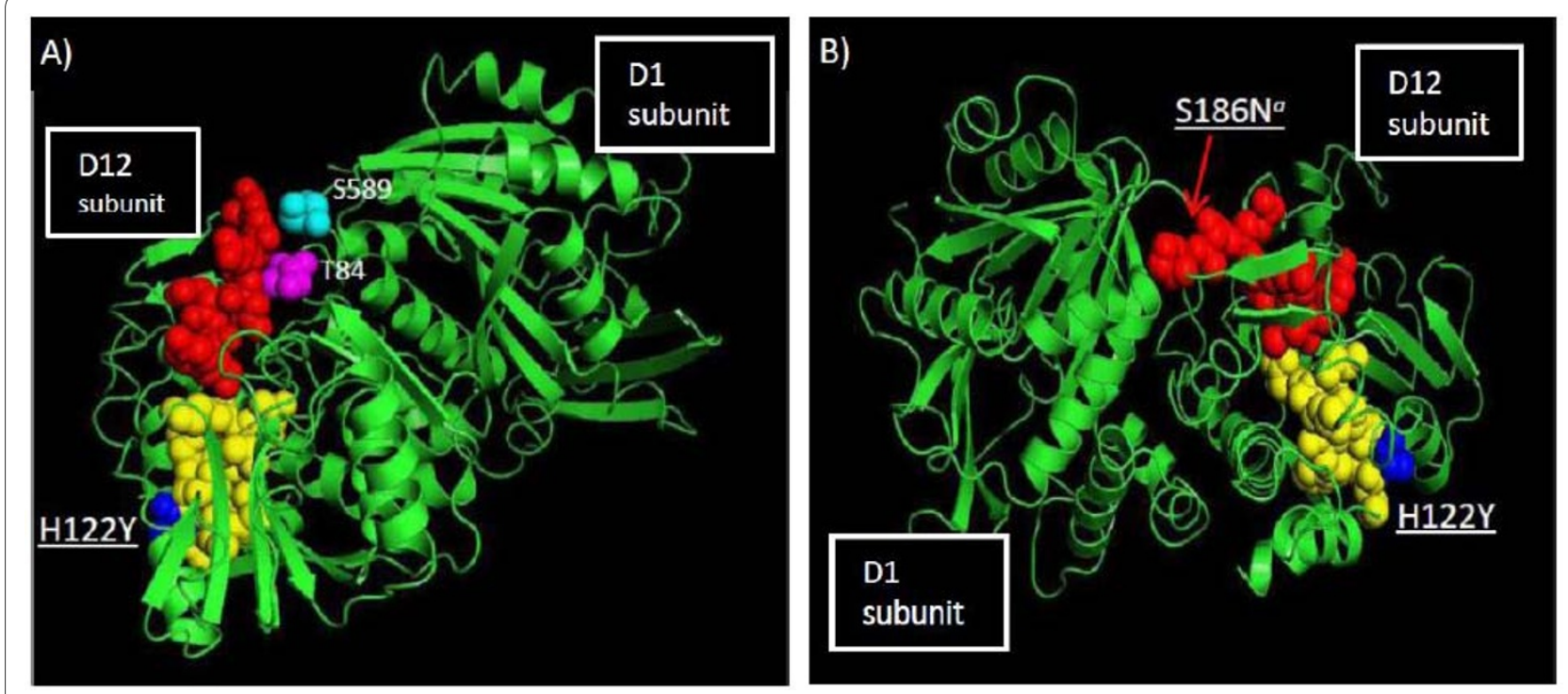

Figure 10 MPV CDV-R mutations mapped onto the 3D structures of the poxvirus D1/D12 mRNA capping enzyme. S186 which lies within the conserved motif 183-KCVSDSWLKDS (F, red residues) plays a major role in proper tertiary folding [54]. Yellow residues (E and F) designate the D12 hetero-dimerization motif [54]. D1 residues T84 (magenta) and S589 (teal) specify residues in closest proximity to the D12 S186N substitution (E). Illustrations were prepared using PyMol. 

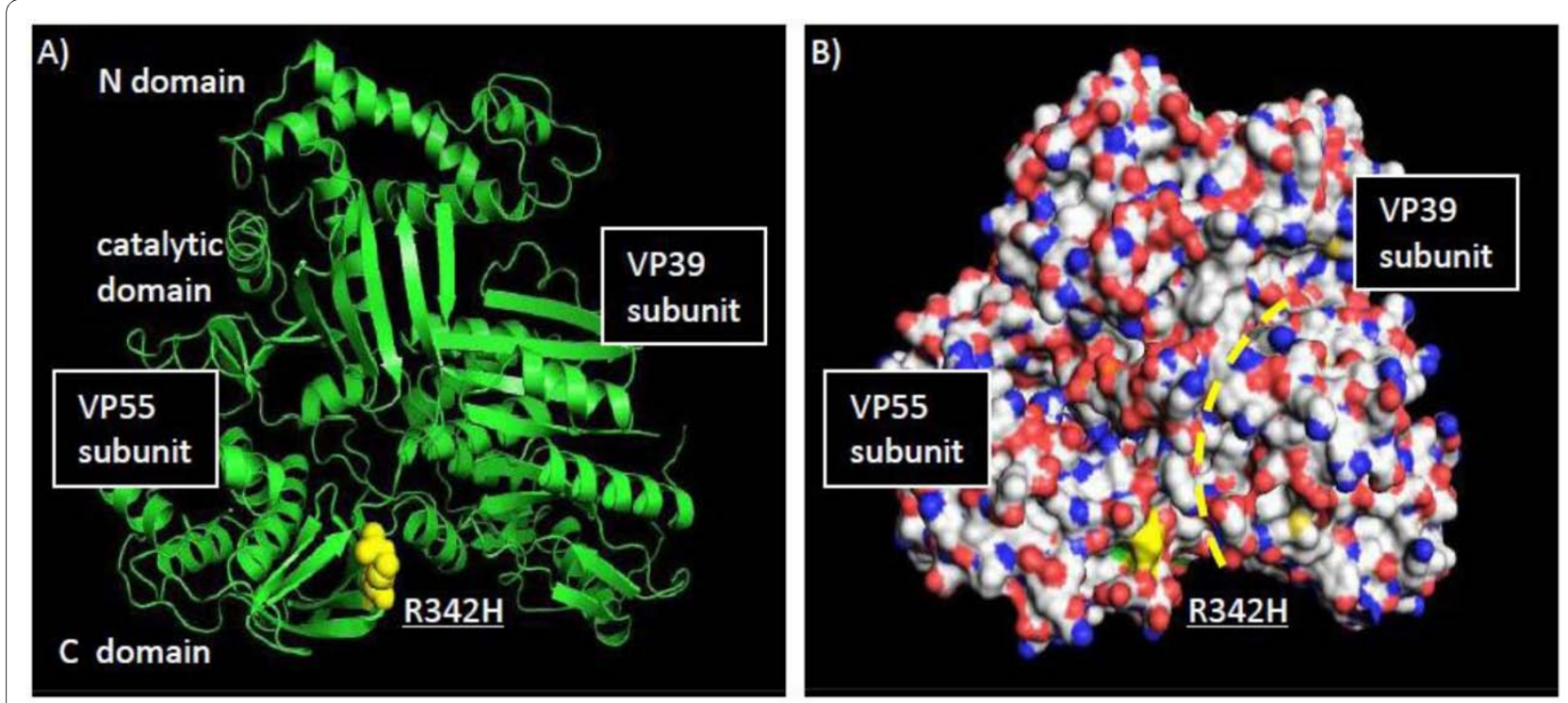

Figure 11 MPV CDV-R mutations mapped onto the 3D structures of poxvirus poly-A polymerase VP55. The R342H mutation (yellow) is presented in the ribbon diagram topology (A) and space filling model (B). Dashed yellow line (B) designates the VP55-VP39 interface.

properties of resistant poxviruses. Furthermore, defining the potential contribution of substitutions in the replication complex and RNA processing machinery may inform current therapeutic development strategies and yield further insight into CDV-resistance and attenuation.

\section{Methods}

Viral DNA extraction, amplification and sequencing

The CDV-R strain of MPV Zaire-005 sequenced in this study was previously characterized by Smee et al 2002 (15). Poxvirus DNA were extracted from virus-infected cells utilizing the Aquapure DNA kit (Bio-Rad, Hercules, CA). Prior experiments demonstrated that the material was noninfectious after $60 \mathrm{~min}$ of incubation at $55^{\circ} \mathrm{C}$ in the Aquapure lysis buffer. The PCR amplification and sequencing primers were designed to cover the entire genome in overlapping fragments of about 500-600 bases. Primers were designed by the aid of PrimerSelect V 7.0.0 (DNASTAR, Madison, WI) using general guidelines for primers design. The criteria were as follows: $\mathrm{Tm}: 48^{\circ} \mathrm{C}$ to $63^{\circ} \mathrm{C}$ (optimum $55^{\circ} \mathrm{C}$ ); $\mathrm{GC}$ content: $30-80 \%$ (optimum 50\%); 3' GC clamp: none; size: 18 to 27 (optimum 20); secondary structure: 0 to 8 with a maximum of 3 bp selfcomplementarities at the 3 ' end. The melting temperature was determined according to Breslauer et al [65].

PCR was performed in $25-\mu \mathrm{l}$ volume containing a PCR buffer (20 mM Tris-HCl, pH 8.4, $50 \mathrm{mM} \mathrm{KCl}$ ), $3 \mathrm{mM}$ $\mathrm{MgCl}_{2}, 0.2 \mathrm{mM} \mathrm{dNTP} \mathrm{mix,} 0.4 \mathrm{uM}$ of each primer forward and reverse, $2 \mathrm{U}$ of Platinum Taq DNA polymerase (Invitrogen Life Technologies, Carlsbad, CA), and 3 pg of DNA template. The amplification reaction was carried using the cycler PTC100 (MJ Research, Reno, NV) with the following cycling conditions: $94^{\circ} \mathrm{C}$ for $2 \mathrm{~min}, 45$ cycles of $94^{\circ} \mathrm{C}$ for $30 \mathrm{sec}, 50^{\circ} \mathrm{C}$ for $15 \mathrm{sec}$, and $72^{\circ} \mathrm{C}$ for $1 \mathrm{~min}$, and one cycle of $72^{\circ} \mathrm{C}$ for $5 \mathrm{~min}$. The PCR product was stored at $4^{\circ} \mathrm{C}$ until use.

Genome sequences were determined by capillary sequencing using the ABI Prism BigDye Terminator Cycle Sequencing Kit 3.1 (Applied Biosystems, Foster City, CA) and the manufacturer's instructions for PCR product sequencing. Cycle sequencing reactions were carried out on MJ Research PTC100 thermal cycler (MJ Research, Reno, NV). Labeled products were analyzed in an ABI 3700 Genetic Analyzer (Applied Biosystems). The resultant sequence reads were assembled into contigs using Lasergene 7 software, (DNASTAR). Consensus DNA sequences were obtained at least 3-fold redundancy at each base locus. The CDV-R MPV genome sequence has been deposited in GenBank under accession No. HM172544.

\section{Genome comparison}

The MEGA 4.0 software package [66] was used for SNP/ indel identification and whole genome sequence comparisons of CDV-R and WT Zaire 79-005. The genome of the seed stock used in the analysis (WT Zaire 79-005) was sequenced and compared with the genome of the final CDV-R passage.

\section{Protein sequence and predictive structural analysis}

MEGA 4.0 was used to generate amino acid alignments. Topological feature maps containing predictive protein secondary structure analysis output was carried out using the Protean module of Lazergene (DNAstar) software under default settings. Motif surface exposure at MVP 
CDV-R substitution loci were estimated using the Jameson-Wolf antigenic index and the Emini method. The antigen index integrates hydropathy, conventional solvent accessibility, and flexibility to produce a linear surface contour plot [67] and provides a more comprehensive surface exposure estimate than the Emini method [68], which evaluates side-chain solvent accessibility alone (i.e., Emini plot). 3-D protein structures were modeled using PyMol software [69] and Cn3D software http:// www.ncbi.nlm.nih.gov/Structure/CN3D/cn3d.shtml.

\section{Competing interests}

The authors declare that they have no competing interests.

\section{Authors' contributions}

JF carried out comparative genome sequence analysis, SNP identification and characterization, protein modeling and drafted the manuscript. MAI performed genome sequencing. $\mathrm{JH}$ developed and isolated CDV-R and WT viruses. SI conceived, directed and coordinated genome sequencing study, prepared project proposal, designed primers and performed sequence assembly. All authors read and approved the final manuscript.

\begin{abstract}
Acknowledgements
This work was supported by research program funds managed by the Defense Threat Reduction Agency (plan no. F_X003_04_RD_B/CB2851). We would like to thank David Evans and Wendy Magee for their technical assistance. We also thank Katheryn Kenyon for editorial review of the manuscript. Opinions, interpretations, conclusions, and recommendations are those of the authors and are not necessarily endorsed by the U.S. Army. The mention of materials or products in this article does not constitute endorsement by the Department of Defense or the United States government. This research was supported in part by an appointment to the Postgraduate Research Participation Program at the U.S. Army Medical Research Institute of Infectious Diseases administered by the Oak Ridge Institute for Science and Education through an interagency agreement between the U.S. Department of Energy and USAMRMC.
\end{abstract}

\section{Author Details}

Virology Division, U.S. Army Medical Research Institute of Infectious Diseases, Fort Detrick, Frederick, MD 21702-5011, USA

Received: 9 April 2010 Accepted: 28 May 2010

Published: 28 May 2010

\section{References}

1. Moss B: Poxviridae: the viruses and their replicaton. In Fields Virology Volume 2. Edited by: Knipe DM. Philadelphia: Lippincott Williams \& Wilkins; 2007:2905-2946.

2. Whitley RJ: Smallpox: a potential agent of bioterrorism. Antiviral Res 2003, 57:7-12

3. Di Giulio DB, Eckburg PB: Human monkeypox: an emerging zoonosis. Lancet Infect Dis 2004, 4:15-25.

4. Hutin YJF, Williams RJ, Malfait P, Pebody R, Loparev VN, Ropp SL, Rodriguez M, Knight JC, Tshioko FK, Khan AS, Szczeniowski MV, Esposito $\mathrm{J}$ : Outbreak of human monkeypox, Democratic Republic of Congo, 1996 to 1997. Emerg Infect Dis 2001, 7:434-438.

5. Fleischauer AT, Kile JC, Davidson M: Evaluation of human-to-human transmission of monkeypox from infected patients to health care workers. Clin Infect Dis 2005, 40:689-694.

6. Beaud G: Vaccinia virus DNA replication: a short review. Biochimie 1995, 77:774-9.

7. De Clercq E: Cidofovir in the treatment of poxvirus infections. Antiviral Res 2002, 55:1-13.

8. De Clercq E, Neyts J: Therapeutic potential of nucleoside/nucleotide analogues against poxvirus infections. Rev Med Virol 2004, 14:289-300.

9. Smee DF, Sidwell RW: A review of compounds exhibiting antiorthopoxvirus activity in animal models. Antiviral Res 2003, 57:41-52.

10. Kornbluth RS, Smee DF, Sidwell RW, Snarsky V, Evans DH, Hostetler KY. Mutations in the E9L polymerase gene of cidofovir-resistant vaccinia virus strain WR are associated with the drug resistance phenotype. Antimicrob Agents Chemother 2006, 50:4038-4043.

11. De Clercq E: Acyclic nucleoside phosphonates: Past, present and future. Bridging chemistry to HIV, HBV, HCV, HPV, adeno-, herpes-, and poxvirus infections: the phosphonate bridge. Biochem Pharmacol 2007, 73:911-922.

12. Magee WC, Hostetler KY, Evans DH: Mechanism of inhibition of vaccinia virus DNA polymerase by cidofovir diphosphate. Antimicrob Agents Chemother 2005, 49:3153-3162.

13. Magee WC, Aldern KA, Hostetler KY, Evans DH: Cidofovir and (S)-9-[3hydroxy-(2-phosphonomethoxy)propyl]adenine are highly effective inhibitors of vaccinia virus DNA polymerase when incorporated into the template strand. Antimicrob Agents Chemother 2008, 52:586-597.

14. De Clercq E: Therapeutic potential of cidofovir (HPMPC, Vistide) for the treatment of DNA virus (i.e. herpes-, papova-, pox- and adenovirus) infections. Verh KAcad Geneeskd Belg 1996, 58:19-47.

15. Smee DF, Sidwell RW, Kefauver D, Bray M, Huggins JW: Characterization of wild-type and cidofovir-resistant strains of camelpox, cowpox, monkeypox, and vaccinia viruses. Antimicrob Agents Chemother 2002, 46:1329-1335

16. Andrei G, Gammon DB, Fiten P, De Clercq E, Opdenakker G, Snoeck R, Evans DH: Cidofovir resistance in vaccinia virus is linked to diminished virulence in mice. $J$ Virol 2006, 80:9391-9401.

17. Gammon DB, Evans D: The 3' -to-5' Exonuclease Activity of Vaccinia Virus DNA Polymerase Is Essential and Plays a Role in Promoting Virus Genetic Recombination. J Virol 2009, 83:4236-4250.

18. Becker MN, Obraztsova M, Kern ER, Quenelle DC, Keith KA, Prichard MN Luo M, Moyer RW: Isolation and characterization of cidofovir resistant vaccinia viruses. Virol J 2008, 5:58

19. Broyles SS: Vaccinia virus transcription.n. J Gen Virol 2003, 84:2293-2303.

20. Gammon DB, Snoeck R, Fiten P, Krecmerová M, Holý A, De Clercq E, Opdenakker G, Evans DH, Andrei G: Mechanism of antiviral drug resistance of vaccinia virus: identification of residues in the viral DNA polymerase conferring differential resistance to antipoxvirus drugs. $J$ Virol 2008, 82:12520-12534.

21. McDonald WF, Klemperer N, Traktman P: Characterization of a processive form of the vaccinia virus DNA polymerase. Virology 1997, 234:168-175.

22. Ishii K, Moss B: Mapping interaction sites of the A20R protein component of the vaccinia virus DNA replication complex. Virology 2002, 303:232-239.

23. Evans $E$, Traktman P: Molecular genetic analysis of a vaccinia virus gene with an essential role in DNA replication. JVirol 1987, 61:3152-3162.

24. Evans E, Klemperer N, Ghosh R, Traktman P: The vaccinia virus D5 protein, which is required for DNA replication, is a nucleic acid independent nucleoside triphosphatase. J Virol 1995, 69:5353-5361.

25. De Silva FS, Moss B: Effects of vaccinia virus uracil DNA glycosylase catalytic site and deoxyuridine triphosphatase deletion mutations individually and together on replication in active and quiescent cells and pathogenesis in mice. Virol $J$ 2008, 2:145.

26. Punjabi A, Boyle K, DeMasi J, Grubisha O, Unger B, Khanna M, Traktman P: Clustered charge-to-alanine mutagenesis of the vaccinia virus $A 20$ gene: temperature-sensitive mutants have a DNA-minus phenotype and are defective in the production of processive DNA polymerase activity. J Virol 2001, 75:12308-12318.

27. Smith GL, De Carlos A, Chan YS: Vaccinia virus encodes a thymidilate kinase gene: sequence and transcriptional mapping. Nucleic Acids Res 1989, 17:7581-7590

28. Caillat C, Topalis D, Agrofoglio LA, Pochet S, Balzarini J, Deville-Bonne D, Meyer P: Crystal structure of poxvirus thymidylate kinase: an unexpected dimerization has implications for antiviral therapy. Proc Natl Acad Sci 2008, 105:16900-16905.

29. Wright CF, Coroneos AM: The $\mathrm{H} 4$ subunit of vaccinia virus RNA polymerase is not required for transcription initiation at a viral late promoter. J Virol 1995, 69:2602-2604.

30. Ahn BY, Gershon PD, Moss B: RNA polymerase-associated protein Rap 94 confers promoter specificity for initiating transcription of vaccinia virus early stage genes. J Biol Chem 1994, 269:7552-7557.

31. Condit RC, Niles EG: Regulation of viral transcription elongation and termination during vaccinia virus infection. Biochim Biophys Acta 2002, 1577:325-336 
32. Shuman S, Surks M, Furneaux H, Hurwitz J: Purification and characterization of a GTP-pyrophosphate exchange activity from vaccinia virions. Association of the GTP-pyrophosphate exchange activity with vaccinia mRNA guanylyltransferase. RNA (guanine-7-) methyltransferase complex (capping enzyme). J Biol Chem 1980, 255:11588-11598.

33. Moss B, Rosenblum EN, Gershowitz A: Characterization of a polyriboadenylate polymerase from vaccinia virions. J Biol Chem 1975 250:4722-4729.

34. Gershon PD: Poly(A) polymerase/cap-specific 28-Omethyltransferase from vaccinia virus: Expression, purification, uses and protein-ligand interaction assays. In Analysis of mRNA Formation and Function, Methods in Molecular Genetics Edited by: Richter J. San Diego: Academic Press; 1997:127-148

35. Oh J, Broyles SS: Host cell nuclear proteins are recruited to cytoplasmic vaccinia virus replication complexes. J Virol 2005, 79:12852-12860.

36. Knutson BA, Liu X, Oh J, Broyles SS: Vaccinia virus intermediate and late promoters are targeted by the TATA binding protein. J Virol 2006 80:6784-6793.

37. Broyles SS, Moss B: Homology between RNA polymerases of poxviruses, prokaryotes, and eukaryotes: Nucleotide sequence and transcriptional analysis of vaccinia virus genes encoding 147-kDa and 22-kDa subunits. Proc Nat Acad Sci 1986, 83:3141-3145.

38. Knutson BA, Broyles SS: Expansion of poxvirus RNA polymerase subunits sharing homology with corresponding subunits of RNA polymerase II. Virus Genes 2008, 2:307-311.

39. Ahn BY, Moss B: RNA polymerase-associated transcription specificity factor encoded by vaccinia virus. Proc Natl Acad Sci 1992, 89:3536-3540.

40. Nudler E: RNA polymerase active center: the molecular engine of transcription. Annu Rev Biochem 2009, 78:335-361.

41. Cramer P, Bushnell DA, Fu J, Gnatt AL, Maier-Davis B, Thompson NE, Burgess RR, Edwards AM, David PR, Kornberg RD: Architecture of RNA polymerase II and implications for the transcription mechanism. Science 2000, 288:640-649.

42. Fish RN, Kane CM: Promoting elongation with transcript cleavage stimulatory factors. Biochim Biophys Acta 2002, 1577:287-307.

43. Kim B, Nesvizhskii Al, Rani PG, Hahn S, Aebersold R, Ranish JA: The transcription elongation factor TFIIS is a component of RNA polymerase II preinitiation complexes. Proc Natl Acad Sci 2007, 104:16068-16073.

44. Vassylyev DG, Svetlov V, Vassylyeva MN, Perederina A, Igarashi N: Structural basis for transcription inhibition by tagetitoxin. Nat Struct Mol Biol 2005, 12:1086-1093.

45. Bushnell DA, Cramer P, Kornberg RD: Structural basis of transcription: aamanitin-RNA polymerase II cocrystal at $28 \mathrm{~A}$ resolution. Proc Natl Acad Sci 2002, 5:1218-22.

46. Bartolomei MS, Corden $\mathrm{J}$ : Clustered a-amanitin resistance mutations in mouse. Mol Gen Genet 1995, 246:778-782.

47. Hagler J, Shuman S: Nascent RNA cleavage by purified ternary complexes of vaccinia RNA polymerase. J Biol Chem 1993, 268:2166-2173.

48. Chen HT, Hahn S: Binding of TFIIB to RNA polymerase II: Mapping the binding site for the TFIIB zinc ribbon domain within the pre-initiation complex. Mol Cell 2003, 12:437-447.

49. Morgan JR, Cohen LK, Roberts BE: Identification of the DNA sequences encoding the large subunit of the mRNA-capping enzyme of vaccinia virus. J Virol 1984, 52:206-214

50. Niles EG, Lee-Chen GJ, Shuman S, Moss B, Broyles SS: Vaccinia virus gene D12L encodes the small subunit of the viral mRNA capping enzyme. Virology 1989, 172:513-522.

51. Shuman S, Broyles SS, Moss B: Purification and characterization of a transcription termination factor from vaccinia virions. J Biol Chem 1987, 262:12372-12380.

52. Vos JC, Sasker M, Stunnenberg HG: Vaccinia virus capping enzyme is a transcription initiation factor. EMBO J 1991, 10:2553-2558.

53. De la Peña M, Kyrieleis OJ, Cusack S: Structural insights into the mechanism and evolution of the vaccinia virus mRNA cap N7 methyltransferase. EMBO J 2007, 26:4913-4925

54. Higman MA, Bourgeois N, Niles EG: The vaccinia virus mRNA (guanineN7-) methyltransferase requires both subunits of the mRNA capping enzyme for activity. J Biol Chem 1992, 267:16430-16437.
55. Mao X, Shuman S: Intrinsic RNA (guanine-7) methyltransferase activity of the vaccinia virus capping enzyme D1 subunit is stimulated by the D12 subunit Identification of amino acid residues in the D1 protein required for subunit association and methyl group transfer. J Bio/ Chem 1994, 269:24472-24479.

56. Saha N, Shuman S: Effects of alanine cluster mutations in the D12 subunit of vaccinia virus mRNA (guanine-N7) methyltransferase. Virology 2001, 287:40-48.

57. Schwer B, Shuman S: Genetic analysis of poxvirus mRNA cap methyltransferase: suppression of conditional mutations in the stimulatory D12 subunit by second-site mutations in the catalytic D1 subunit. Virology 2006, 352:145-156

58. Zheng S, Shuman S: Mutational analysis of vaccinia virus mRNA cap (guanine-N7) methyltransferase reveals essential contributions of the $\mathrm{N}$-terminal peptide that closes over the active site. RNA 2008, 14:2297-2304

59. Parrish S, Moss B: Characterization of a vaccinia virus mutant with a deletion of the D10R gene encoding a putative negative regulator of gene expression. J Virol 2006, 80:553-561

60. Gershon PD, Moss B: Transition from rapid processive to slow nonprocessive polyadenylation by vaccinia virus poly $(A)$ polymerase catalytic subunit is regulated by the net length of the poly(A) tail. Gen Dev 1992, 6:1575-1586.

61. Shi X, Bernhardt TG, Wang SM, Gershon PD: The surface region of the bifunctional vaccinia RNA modifying protein VP39 that interfaces with Poly $(A)$ polymerase is remote from the RNA binding cleft used for its mRNA 5' cap methylation function. J Biol Chem 1997, 272:23292-23302.

62. Deng L, Johnson JM, Neveu S, Hardin SM, Wang WS, Lane PD, Gershon A: Polyadenylylation-specific RNA-contact site on the surface of the bifunctional vaccinia virus RNA modifying protein VP39 that is distinct from the mRNA 5' end-binding "cleft". J Mol Biol 1999, 285:1417-1427.

63. Moure CM, Bowman BR, Gershon PD, Quiocho FA: Crystal structures of the vaccinia virus polyadenylate polymerase heterodimer: Insights into ATP selectivity and processivity. Mol Cell 2006, 33:339-349.

64. Deng L, Gershon PD: Interplay of two uridylate-specific RNA binding sites in the translocation of poly $(A)$ polymerase from vaccinia virus. EMBO J 1997, 16:1103-1113.

65. Breslauer KJ, Frank R, Blocker H, Marky LA: Predicting DNA duplex stability from the base sequence. Proc Nat/ Acad Sci 1986, 83:3746-3750.

66. Tamura K, Dudley J, Nei M, Kumar S: MEGA 4.0: Molecular evolutionary genetics analysis (MEGA) software version 4.0. Mol Bio Evol 24:1596-1599.

67. Jameson BA, Wolf H: The antigenic index: a novel algorithm for predicting antigenic determinants. CABIOS 1988, 4:181-186.

68. Emini EA, Hughes JV, Perlow DS, Boger J: Induction of Hepatitis A virus neutralizing antibody by a virus-specific synthetic peptide. J Virol 1985 , 55:836-839.

69. DeLano W: PyMol: An open-source molecular graphics tool. [http:// www.ccp4.ac.uk/newsletter/newsletter40/11 pymol.pdf]. DeLano Scientific LLC

70. Kettenberger $\mathrm{H}$, Armache KJ, Cramer P: Complete RNA polymerase II elongation complex structure and its interactions with NTP and TFIIS. Mol Cell 2004, 16:955-965.

doi: $10.1186 / 1743-422 X-7-110$

Cite this article as: Farlow et al., Comparative whole genome sequence analysis of wild-type and cidofovir-resistant monkeypoxvirus Virology Journal 2010, 7:110 